\title{
Automatic Information Processing Bias to Stress Factors by Older Adults with and without Diabetes
}

\author{
Perla Lizeth Hernández-Cortés ${ }^{1}$, López Ramírez Ernesto Octavio², \\ Guadalupe Elizabeth Morales Martínes² ${ }^{2}$ Bertha Cecilia Salazar-González ${ }^{1}$ \\ ${ }^{1}$ School of Nursing, Universidad Autonoma de Nuevo Leon, San Nicolás de los Garza, Mexico \\ ${ }^{2}$ Department of Psychology, Universidad Autonoma de Nuevo León, San Nicolás de los Garza, Mexico \\ Email: elopez42@att.net.mx
}

Received 6 May 2014; revised 18 June 2014; accepted 23 July 2014

Copyright (C) 2014 by authors and Scientific Research Publishing Inc.

This work is licensed under the Creative Commons Attribution International License (CC BY). http://creativecommons.org/licenses/by/4.0/

c) (i) Open Access

\section{Abstract}

A sample of 65 older adults (with and without diabetes) as well as a sample of 84 healthy young people were required to take affective priming studies to compare recognition latencies of stress related word pairs against recognition latencies of positive, negative and neutral word pairs. Moreover, older adults took a stress questionnaire related to relevant disturbing events in the third age. The goal was to test any automatic emotional processing bias to these events. Results suggested that even when people with diabetes obtained low stress test scores, they showed automatic cognitive bias to process stressful events differently than older adults without diabetes and young people. This suggested that people with diabetes patients' controlled strategies to cope with stress might not be aware of such an automatic cognitive bias. It is argued that this information processing style to stressful events makes patients prone to cognitive emotional vulnerability.

\section{Keywords}

Aging, Positivity, Diabetes, Stress, Automatic Cognitive Bias

\section{Introduction}

There is no doubt that in late life, older adults have to cope with physical (health problems), mental (decrease of cognitive capacities or cognitive deficits due to illness), and social stressors (abandonment or family loses) with an increasing frailty, which threaten their quality of life [1].

Models of successful aging [2] suggest that in order to cope with late life stressors, older adults proactively 
plan in anticipation to meet challenges of aging. Specifically, proactivity models of successful aging describe how older people choose behavioral adaptations to cope with stressors of illness, frailty and social loses [3] [4]. Here, in terms of psychological well-being, enhancement of emotional experience seems to be an available mental resource that people use in late life to proactively adapt to mental or/and physical decline. This is the case for health effects of positivity in old adults where academic evidence suggests that positive emotional experience is a relevant predictor of survival in late stages of life [5]. Regarding the intellectual decline in late life, positivity becomes a relevant cognitive resource that can be used as an active coping style. Take for instance that when older people are compared to young adults in a working memory visual task, older adults perform significantly poorer than younger adults. However, if the cognitive memory task requires to deal with visual emotional content, both groups show the same level of performance over negative information and older adults exhibit superior working memory performance to process positive information compared to negative emotional stimuli [7].

This positivity effect has led to question about the possibility of regulatory processes whose function is to sustain or increase positive emotional experience. Cognitively speaking, there is some scarce initial academic evidence supporting this possibility. For instance, it is known that older adults tend to activate attention processes to avoid negative stimuli and to facilitate recognition of positive stimuli [8] [9], and they remember more positive stimuli [7] and contextualize their decisions inside a positive framework. This emotional information processing preference might relate to a mood regulation process that serves to better adaptation for survival [10]. If so, it is not clear if positive emotional resources are of limited utility to enhance health under all stressful situations. Say, life-threatening illness like diabetes. Is it possible that positivity leads to mal adaptive instead of adaptive mental and behavioral health consequences? It has been suggested in current academic literature that in order to obtain a state of optimal well-being in late life health, a ratio of positive to negative emotion at or above 2.9 to 1 must be achieved by old people [11]-[13]. Minimizing negativity in relation to positivity could be related to dysfunctional behavior. For example, even when many people with diabetes know the negative consequences of consuming sugar, they do frequently consume unhealthy sugar-contained food. They do this under the rationale that they want to live "happily", which is left of their life. Unfortunately, not much is known about how cognitive-emotion functioning interacts to affect judgment over stressful events (like an illness) in later stages of life. For instance, most cognitive research on positivity is mainly related to studies of cognitive controlled processing.

Traditionally nursing research has used scales of fixed options using adjectives that stand for a predeterminated value to signify some amount of the attribute as perceived by the participant. These formats allow participants to reason their responses and in some instances to introduce bias or social desirability. Thus participants may manipulate and control the information they are providing. It is also possible that dissonant implicit or biased automatic processing affects psychological well-being and it relates to mal adaptive behavior during illness. Certainly, this non-conscious behavior is not necessary in accordance to a person's beliefs or controlled cognitive reports.

Furthermore, understanding how older adults (positive/negative) evaluate emotional information related to health related events is relevant to anticipating a patient's adherence to treatment or healthy behaviors. This is the case for prediction models of behavior like the Theory of Planned Behavior (TPB) where consideration of affective cognitions seems to increase its predictive power [14].

The current study implements a set of cognitive studies to explore if people with diabetes do indeed differentiate negativity from disturbing events related to third age health outcomes and if they possess a specific cognitive emotional processing system tuned to deal with third age stressful events.

\section{Method}

\subsection{Pilot Study: Establishment of Emotional Relevant Stressful Words}

This initial study sought to establish if a set of words related to stress factors in adulthood are recognized as emotional different from standard emotional word stimuli sets (positive, negative, neutral). The goal was to identify a set of stressful words that can be identified by cognitive automatic emotional processing in older people. 


\subsubsection{Sample}

A sample of 84 healthy psychology bachelor Mexican students (48 women, 36 men) participated in this study. Their age interval varied between 18 and 25 years old. This sample was used to compare their automatic emotional processing performance of stressful events against next study older adults' recognition of stress words. In addition, this group of people was used to test for recognition of stressful words as a different stimuli set from other emotional words (e.g., positive; negative). It was expected that even when the stressful words relate more to third age events these words could also be recognized as emotional different by young adults.

\subsubsection{Instrument}

An affective priming study was implemented to compare recognition times of emotional words against recognition latencies of stressful words. The affective priming paradigm began as an experimental technique presented by Fazio [15] to study how the emotional valence of a stimulus (prime) affects the recognition of other valenced stimuli (target). The affective priming effect has proven to be a robust psychological effect and it has been tested by using a wide variety of stimuli [16].

\subsubsection{Stimuli}

Experimental stimuli used combinations of emotional congruent word pairs (Positive/Positive, Negative/Negative, Stress/Stress and Neutral/Neutral) and emotional incongruent word pairs (Negative/Positive, Stress/Positive, Stress/Negative, Positive/Stress, Negative/Stress and Stress/Neutral). Stimuli used to create the experimental stimuli set are presented in Table 1. Word size as well as word frequency (by using the LEXEXP Spanish word dictionary) were controlled. Positive, Negative and neutral words are taken from standard affective priming ex-

\begin{tabular}{cccc} 
Table 1. Emotional words used to create the affective priming word pairs stimuli. & \\
\hline POSITIVE & NEGATIVE & STRESS & NEUTRAL \\
\hline HAPPINES & DIFFICULT & LONELINESS & SOCK \\
JOY & ANGER & ABANDONMENT & SCREW \\
FRIENDLY & RESENTMENT & DEATH & WINDOW \\
HONEST & EVIL & AILMENTS & SPRING \\
HOPE & SADNESS & SICKNESS & NOTEBOOK \\
GIFT & DISSAPOINTED & OLD-AGE & RIBBON \\
ILUSION & SHOUT & PROBLEMS & DOOR \\
WIN & AGRESSION & HOSPITAL & GUITAR \\
BEATIFUL & WOUND & LOST & WOOD \\
GENEROUS & FAINT & MONEY & HAT \\
SMILE & HORROR & FUTURE & MAGAZINE \\
PRETTY & TORTURE & MEDICINE & HAIBRUSH \\
LOVE & FAIL & DEPENDENCE & BYCICLE \\
BRILLIANT & CRYING & FORGET & SHOE \\
CHEERFUL & HUMILLIATE & MEMORY & FAN \\
AFFECTION & HIT & FAMILY & STOCKING \\
KIND & SUFFER & BASKET \\
FRIENDSHIP & LOST & DISCONFORT & BALL \\
HUG & FRIGHTEN & SERIOUSNESS & TELEPHONE \\
PRESENT & DECEPTION & DEPRESSION & \\
\hline
\end{tabular}


periments [16]. Stress words were selected from a third age stress scale questionnaire [17] (see the instrument section in the main study) by three judges whose research is related to cognition and emotion.

Mood incongruent word pairs are relevant to this study because they allowed inspection about how emotional primes contribute to emotional valence recognition of a target. Relevant to this study are contributions of positive and negative primes to recognition of words describing stressful events.

\subsubsection{Procedure}

Each subject attended to a 60 minutes individual session with a trained researcher. Each one sat in front of a computer and instructions were provided until they understood the experimental cognitive task very well. The experimental trails were as follows. First, a point at the center of the computer screen appeared to allocate participant's gaze at the center of the computer screen. Then, word with or without emotion appeared for 250 milliseconds followed by a white interval of 50 milliseconds. Finally, another word with or without emotion appeared and stayed at the computer screen until the participant decided if this last word was emotional or neutral. The computer user had to press the letter "Z" in the computer keyboard that had a red paper on it with the "YES" word written on it to indicate the word was emotional or to press the letter "M" that had a green paper that had the "NO" word if the presented word had no emotion.

After instructions, a practice session was required. Only after subjects declared full understanding of the experimental task then experimental trials were presented. The whole study took approximately 20 minutes.

\subsubsection{Results}

A repeated measure ANOVA was carried on over congruent emotional word pairs. All participants were included since they provided more than $90 \%$ correct latencies. As expected, the results showed a significant main effect for the type of word relation factor, $\mathrm{F}(3,249)=18,797, \mathrm{p}=0.00000, \eta_{\mathrm{p}}^{2}=0.184650$. Regarding recognition of stress related word pairs an analytical post hoc comparison showed significantly slower recognition latencies than the rest of emotional word pairs $F(1,83)=34,174, p=0.0000$. Figure 1 shows participants' performance through all of the experimental conditions. It can be observed from the graph that participants discriminate between emotions and neutral information and that they seem to use more cognitive resource to valuate stress information.

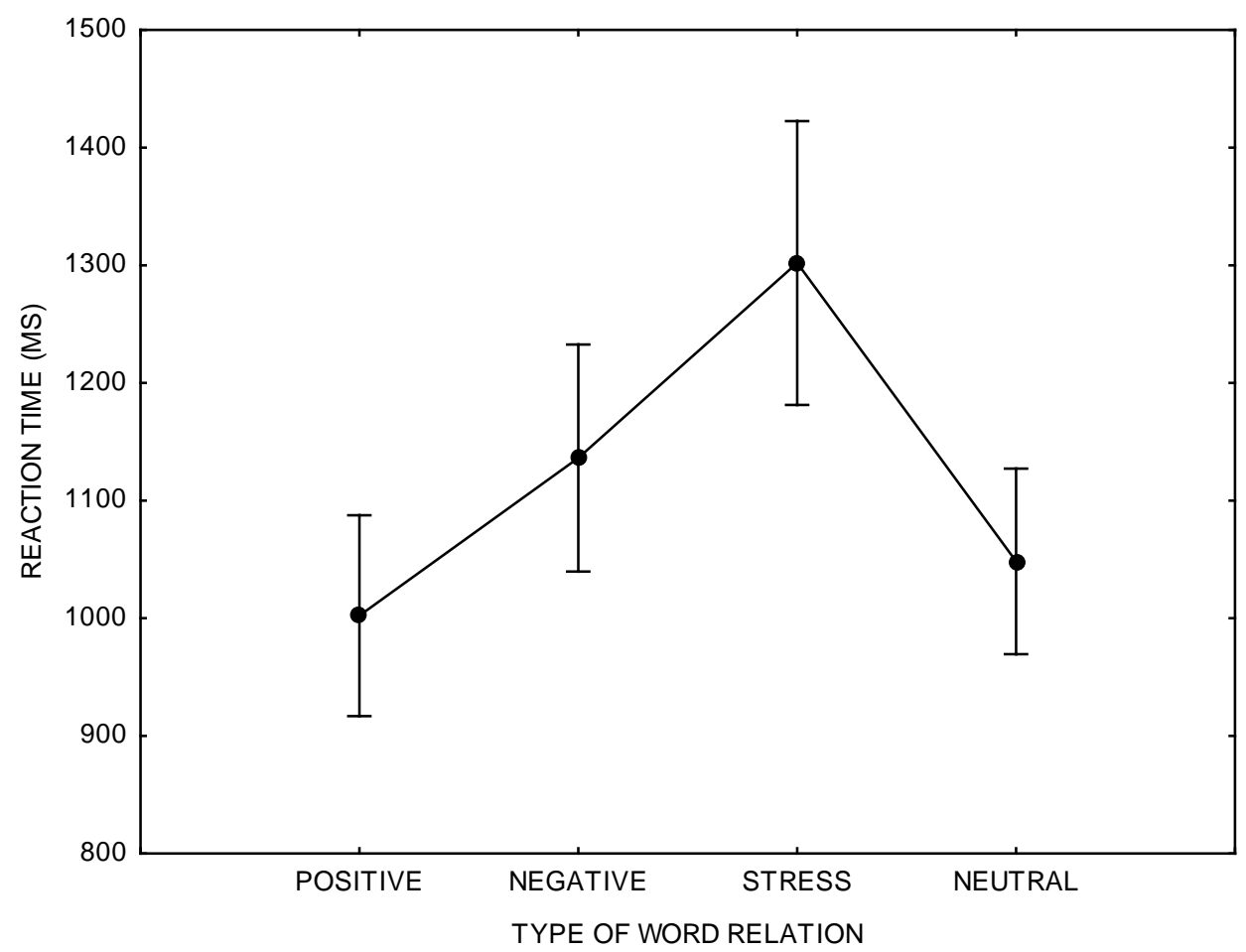

Figure 1. Participants recognized stress words as an emotional different set from other emotion and non-emotional words. 


\subsection{Main Study: Automatic Emotional Processing of Stressful Events by Old Adults with and without Diabetes}

This study was implemented to test for automatic emotional processing differences between older adults with a diabetic condition versus healthy young and old persons. The hypothesis underlying this research intention is that even when people with diabetes might explicitly report no affection by stressful events (e.g., positivity) they do possess cognitive bias to automatically process stressful information that does not agreed with their controlled cognition to cope their illness.

\subsubsection{Sample}

Sixty five older adults (19 with diabetes and 35 without diabetes) from a North City of Mexico voluntarily agreed to participate in this study. Their age interval ranged between 62 and 78 years old (Mean = 68.93; SD = 3.77). Older adults with Diabetes (11 women and 8 men) had this physical condition more than 10 years (Mean $=11.19$, $\mathrm{SD}=8.42$ ). Institutional as well as ethical committee consent was obtained to access sample participants (from 10 Mexican government institutions attending third age people).

\subsubsection{Instrument}

The same affective priming study used in the pilot study was considered for this study. In addition, third age participants were required to take the Spanish third age stressful events scale [16] [17] (In Spanish: EAE-A). This stress questionnaire is addressed to people whose age ranks between 65 and 85 years. The test consists of 51 items and it checks for psychological and physical wellbeing as well as for economic status and social life. Specifically, the goal of this test is to know: a) The number of stressful events a person has suffered, b) the intensity of each disturbing event and c) to know if the person still affected by those events. Obtained final stress scores vary from 0 to 153 . Scores higher than 89 reveal stress affection. It takes approximately 20 minutes to complete the test.

\subsubsection{Procedure}

Most affective priming applications were carried over through personal individual sessions. Only one participant took the study through an internet version of it as the one used by the young students sample. The appointed experimental procedure in the pilot study was used in this study as well.

\subsubsection{Results}

All third age participants reported not to be under stress. They obtained very low EAE-A (Mean = 29 pts.; SD = 23.64). Regarding the affective priming studies, a first analysis, 2 (type of group: Older adults vs. Young adults) $\times 4$ (type of emotional relation: Positive, Negative, Neutral, Stress) mixed ANOVA was carried on over congruent emotional word pairs. Older adults made more recognition mistakes than young adults. Therefore, the inclusion criterion in the statistical analysis was to consider participants with $80 \%$ or more correct answers.

Results showed a significant main effect to both factors. Specifically, as expected older adults has significant slower latencies than youngers, $\mathrm{F}(1,96)=42.743, \mathrm{p}=0.0000, \eta_{\mathrm{p}}^{2}=0.30$ and the type of relation manipulation significant affected emotional recognition, $\mathrm{F}(3,288)=10.265, \mathrm{p}=0.0000, \eta_{\mathrm{p}}^{2}=0.096$.

Figure 2 displays a factor interaction graph that visually shows emotional recognition performance results of older adults compared to young adults' performance from the pilot study.

A second analysis, 2 (Type of group: Persons with diabetes and without diabetes) $\times 4$ (type of emotional relation: Positive, Negative, Stress) mixed ANOVA was carried on over congruent emotional word pairs. Again, the inclusion criterion in the statistical analysis was to consider participants with $80 \%$ or more correct answers. Here, no significant main effect for type of group was found $\mathrm{F}(3,147)=0.49640, \mathrm{p}=0.68534$ but a significant effect was obtained from manipulation of type of relation among stimuli $\mathrm{F}(3,147)=11.648, \mathrm{p}=0.0000, \eta_{\mathrm{p}}^{2}=$ 0.192061 . As it was the case for young people from the pilot study, stress words had significant slower latencies from the rest of word pairs in the experiment as it is stated by an analytical comparison $F(1,49)=28.38, \mathrm{p}=$ 0.0000. Notice from Figure 2 that this last comparison suggests that older adults consume more cognitive resources (for stressful information) than young adults.

Noticeable to this study was a significant performance difference between participants who recognized themselves having diabetes and old participants without diabetes (the only difference) whenever they had to recognize 


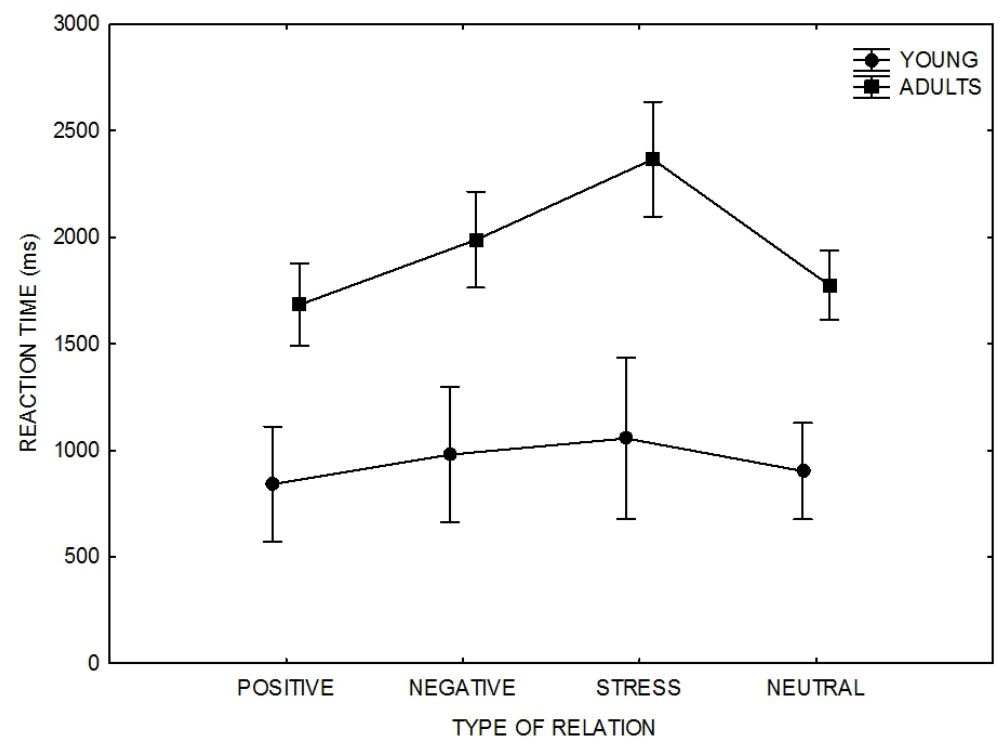

Figure 2. Older adults were significantly slower than the younger ones to recognize emotional congruent words and they use more automatic cognitive resources to process stressful information.

positive information. An analytical comparison showed a significant recognition latency difference between both groups $F(1,49)=5.0025, p=0.0298$. Older adults with diabetes took 422 milliseconds more than non-diabetics to recognize positive information which implies an automatic cognitive bias to consume more cognitive resources to process stressful information. This is interesting since people with diabetes obtained low stress scores when they took the EAE-A stress scale test (more on this will be discussed later).

Regarding incongruent word pairs, results suggest that older adults' automatic cognitive processing system is tuned to impose more emotional relevance to disturbing events than young people, despite they have diabetes or not. Take for example the interaction graph showing how emotional word primes affect recognition of targets in Figure 3. Specifically, note faster target recognition to older adults (top right panel) than for young adults (top left panel). Here, four participants with diabetes and four old participants without this condition were omitted from the analysis because they have more than the allowed $20 \%$ of recognition errors. On the other hand only two young adults were excluded from the analysis by the same reason.

A relevant data pattern in Figure 3 is the recognition of positive targets. Notice that young participants obtained the second faster recognition times for these positive stimuli when these targets are preceded by positive or negative automatic processing activation. This is not true for older adults since positive targets are recognized as the fastest (top right) no matter if they have diabetes (bottom left) or not (bottom right). This change of emotional processing style is congruent with the idea of mood positivity in adulthood because positive targets were strongly primed by all prime stimuli. Another relevant performance result from Figure 3 was the fastest recognition of positive information due to identification of stressful events no matter the sample age. Disturbing events seem to activate fast recognition of positive stimuli. Notice that this is not the case for negative primes. Thus, this result may imply that disturbing events are not the same as their negative connotation.

\section{Discussion}

There is evidence suggesting that young adults process negative information more thoroughly than positive information in impression formation, memory, and decision-making [18]. This is congruent with the current study results. Notice for instance from Figure 3 that valence identification latencies to negative targets were the fastest for young adults if they were primed by emotional information. This was not the case for third age people who identified positive targets more rapidly than other stimuli, regardless if they had diabetes or not. This result may be explained by the positivity effect described in the introduction [5] [6]. It seems that old people's positive mood states facilitate recognition of any kind of emotional events even if these targets are preceded by negative connotation. A significant emotional identification difference to congruent positive targets between older adults 

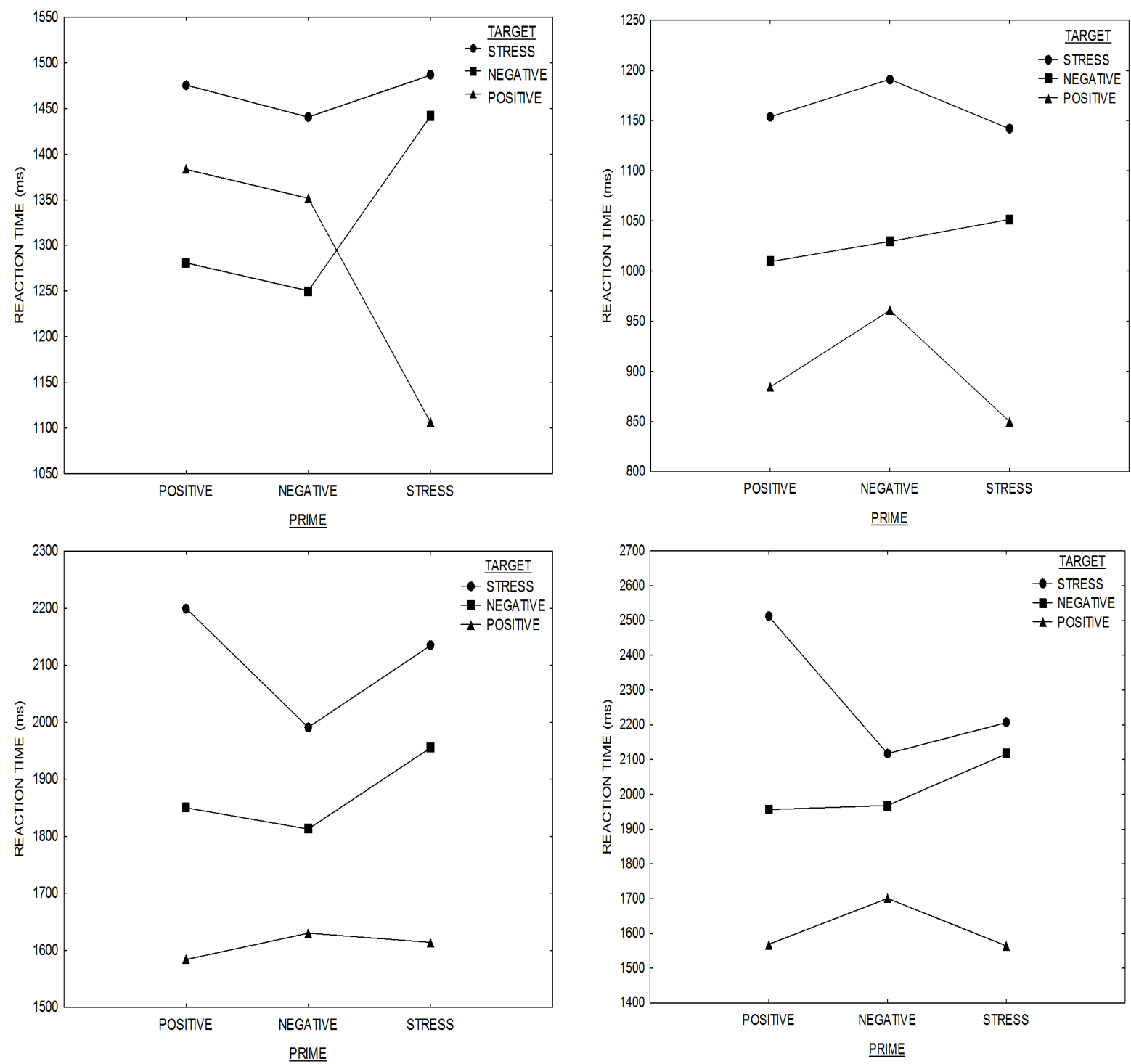

Figure 3. Interaction graphs (incongruent mood prime vs. targets) for young adults (top left), all older people sample (top right), with diabetes (bottom left) and without diabetes (bottom right).

with diabetes and older adults without diabetes makes no difference to this positivity effect.

The fact that people under a diabetic condition require more time/cognitive resource to identify positive targets should bring attention. This is so since cognitions mediate the relation between events that people experience and the emotions that they feel [19]. In particular, dysfunctional thinking and information processing bias is hypothesized to play a cognitive mediator role in the causal chains by which certain cognitively vulnerable individuals develop an emotional disorder (e.g., depression or anxiety) [20]. In this context, a cognitive vulnerability can be understood as a mental mechanism that shapes the individual's selective processing, attention, and memory, and shapes the individual's thinking (i.e., the ideation or automatic thoughts) [21]. Here, interactions of cognitive vulnerability-stress factors can lead to psychological and health problems depending of each person's vulnerability type [22].

Positivity might constitute a resilience mechanism that leads a person to have less cognitive vulnerability. It is not clear if older adults with diabetes' slower latencies to positive latencies represent dysfunctional processing bias [20] but they do process differently positive information which in turn can produce cognitive vulnerability depending on each case (vulnerability depends on accumulative factors of a person's life span: family dysfunction, and child abuse). Resilience to stressful events is relevant in later stages of life because it relates to health 
outcomes and survival [23] [24].

Disturbing events (stress words) were always cognitively relevant to all study samples. These events required more cognitive activation (Figure 2), primed strongly facilitated recognition of positive information in mood incongruent priming (Figure 3) and were constrained as a different class of stimuli (e.g., other than negative information). The reason why stress events relate this way to positive information is unclear and more research is needed. It could be the case of a coping mechanism relating to a positive approach over disturbing mechanisms. Interestingly enough, none of the participants with diabetes explicitly reported to be under stress (low stress test scores). However, this cognitive controlled stress report indicates they are not aware of a complete health coping strategy picture. They do possess a cognitive emotional processing bias to disturbing events (take more processing time than young adults) and they process positive information in a different way.

All in all, this kind of analysis (affective priming methods) seems to be useful not only to bring awareness to people with diabetes about a possible dysfunctional emotional bias but to be a diagnostic tool to observe the impact of nursing interventions and follow-up of medical treatment over dysfunctional emotional processing to disturbing events during the third age. This cannot be achieved by only considering explicit report questionnaire.

\section{References}

[1] De Paula Couto, M.C., Koller, S.H. and Novo, R. (2001) Stressful Life Events and Psychological Well-Being in a Brazilian Sample of Older Persons: The Role of Resilience. Ageing International, 36, $492-505$. http://dx.doi.org/10.1007/s12126-011-9123-2

[2] Pruchno, R.A., Wilson-Genderson, M. and Cartwright F. (2010) A Two-factor Model of Successful Aging. The Journals of Gerontology. Series B, Psychological Sciences and Social Sciences, 65, 671-679. http://dx.doi.org/10.1093/geronb/gbq051

[3] Kahana, E., Kelley, M.J. and Kahana, B. (2011) Proactive Aging: A Longitudinal Study of Stress, Resources, Agency, and Well-Being in Late Life. Aging \& Mental Health, 16, 438-451. http://dx.doi.org/10.1080/13607863.2011.644519

[4] Aspinwall, L.G. (2005) The Psychology of Future-Oriented Thinking: From Achievement to Proactive coping, Adaptation, and Aging. Motivation and Emotion, 29, 203-234. http://dx.doi.org/10.1007/s11031-006-9013-1

[5] Carstensen, L.L., Turan, B., Scheibe, S., Ram, N., Ersner-Hershfield, H., Samanez-Larkin, G.R., Brooks, K.K. and Nesselroade, J.R. (2011) Emotional Experience Improves with age: Evidence Based on over 10 Years of Experience Sampling. Psychology and Aging, 26, 21-33. http://dx.doi.org/10.1037/a0021285

[6] Chida, Y. and Steptoe, A. (2008) Positive Psychological Well-Being and Mortality: A Quantitative Review of Prospective Observational Studies. Psychosomatic Medicine, 70, 741-756. http://dx.doi.org/10.1097/PSY.0b013e31818105ba

[7] Carsten, L.L. and Mikels, J.A. (2005) At the Intersection of Emotion and Cognition: Aging and the Positivity Effect. Current Directions in Psychological Science, 14, 117-121. http://dx.doi.org/10.1111/j.0963-7214.2005.00348.x

[8] Isaacowitz, D.M., Wadlinger, H.A., Goren, D. and Wilson, H.R. (2006) Is There an Age-Related Positivity Effect in visual Attention? A Comparison of Two Methodologies. Emotion, 6, 511-516. http://dx.doi.org/10.1037/1528-3542.6.3.511

[9] Isaacowitz, D.M., Wadlinger, H.A., Goren, D. and Wilson, H.R. (2006) Selective Preference in Visual Fixation away from Negative Images in Old Age? An Eye-Tracking Study. Psychology and Aging, 21, 40-48. http://dx.doi.org/10.1037/0882-7974.21.1.40

[10] Isaacowitz, D.M. and Blanchard, F.F. (2012) Linking Process and Outcome in the Study of Emotion and Aging. Perspectives on Psychological Science, 7, 3-17. http://dx.doi.org/10.1177/1745691611424750

[11] Fredrickson, B.L. \& Losada, M.F. (2005). Positive Affect and the Complex Dynamics of Human Flourishing. American Psychologist, 60, 678-686. http://dx.doi.org/10.1037/0003-066X.60.7.678

[12] Waugh, C.E. and Fredrickson, B.L. (2006) Nice to Know You: Positive Emotions, Self-Other Overlap, and Complex Understanding in the Formation of a New Relationship. The Journal of Positive Psychology, 1, 93-106. http://dx.doi.org/10.1080/17439760500510569

[13] Ong, A.D., Burrow, A.L. and Fuller, R.T.E. (2010) Positive Emotions and the Social Broadening Effects of Barack Obama. Cultural Diversity and Ethnic Minority Psychology, 18, 424-428. http://dx.doi.org/10.1037/a0029758

[14] McEachan, R.R.C., Conner, M., Taylor, N.J. and Lawton, R.J. (2011) Prospective Prediction of Health-Related Behaviors with the Theory of Planned Behavior: A Meta-Analysis. Health Psychology Review, 5, 97-144. http://dx.doi.org/10.1080/17437199.2010.521684

[15] Fazio, R.H. (1995) Attitudes as Object-Evaluation Associations: Determinants, Consequences, and Correlates of Attitude Accessibility. In: Petty, R.E. and Krosnick, J.A., Eds., Attitude Strength: Antecedents and Consequences, Erlbaum, 
Hillsdale, 247-282.

[16] Musch, J. and Klauer, K.C. (2003) The Psychology of Evaluation: An Introduction. In: Musch, J. and Klauer, K.C., Eds., The Psychology of Evaluation: Affective Processes in Cognition and Emotion, LEA, Mahwa, 1-5.

[17] Seara, F. and Robles, M. (2006) EAE Escalas de aprecición del estress. España: TEA Editions, Madrid.

[18] Baumeister, R.F., Bratslavsky, E., Finkenauer, C. and Vohs, K.D. (2001) Bad Is Stronger than Good. Review of General Psychology, 5, 323-370. http://dx.doi.org/10.1037/1089-2680.5.4.323

[19] Power, M. and Dalgleish, T. (2008) Cognition and Emotion: From Order to Disorder. 2nd Edition, Psychology Press, New York.

[20] Williams, J.M.G., Watts, F.N., MacLeod, C. and Mathews, A. (1997) Cognitive Psychology and Emotional Disorders, 2nd Edition, Willey, Chichester.

[21] Riskind, J.H. and Alloy, L.B. (2006) Cognitive Vulnerability to Emotional Disorders: Theory and Research Design/Methodology. In: Alloy, L.B. and Riskind, J.H. Eds., LEA, Mahwa.

[22] Alloy, L.B. and Riskind, J.H. (2010) Cognitive Vulnerability to Emotional Disorders. LEA, Mahwa, New Jersey, USA.

[23] Tugade, M.M., Fredrickson, B.L. and Barret, L.F. (2004) Psychological Resilience and Positive Emotional Granularity: Examining the Benefits of Positive Emotions on Coping and Health. Journal of Personality, 72, 1161-1190. http://dx.doi.org/10.1111/j.1467-6494.2004.00294.x

[24] Ong, A.D., Mroczek, D.K. and Riffin, C. (2011) The Health Significance of Positive Emotions in Adulthood and Later Life. Social and Personality Psychology Compass, 5, 538-551. http://dx.doi.org/10.1111/j.1751-9004.2011.00370.x 
Scientific Research Publishing (SCIRP) is one of the largest Open Access journal publishers. It is currently publishing more than 200 open access, online, peer-reviewed journals covering a wide range of academic disciplines. SCIRP serves the worldwide academic communities and contributes to the progress and application of science with its publication.

Other selected journals from SCIRP are listed as below. Submit your manuscript to us via either submit@scirp.org or Online Submission Portal.
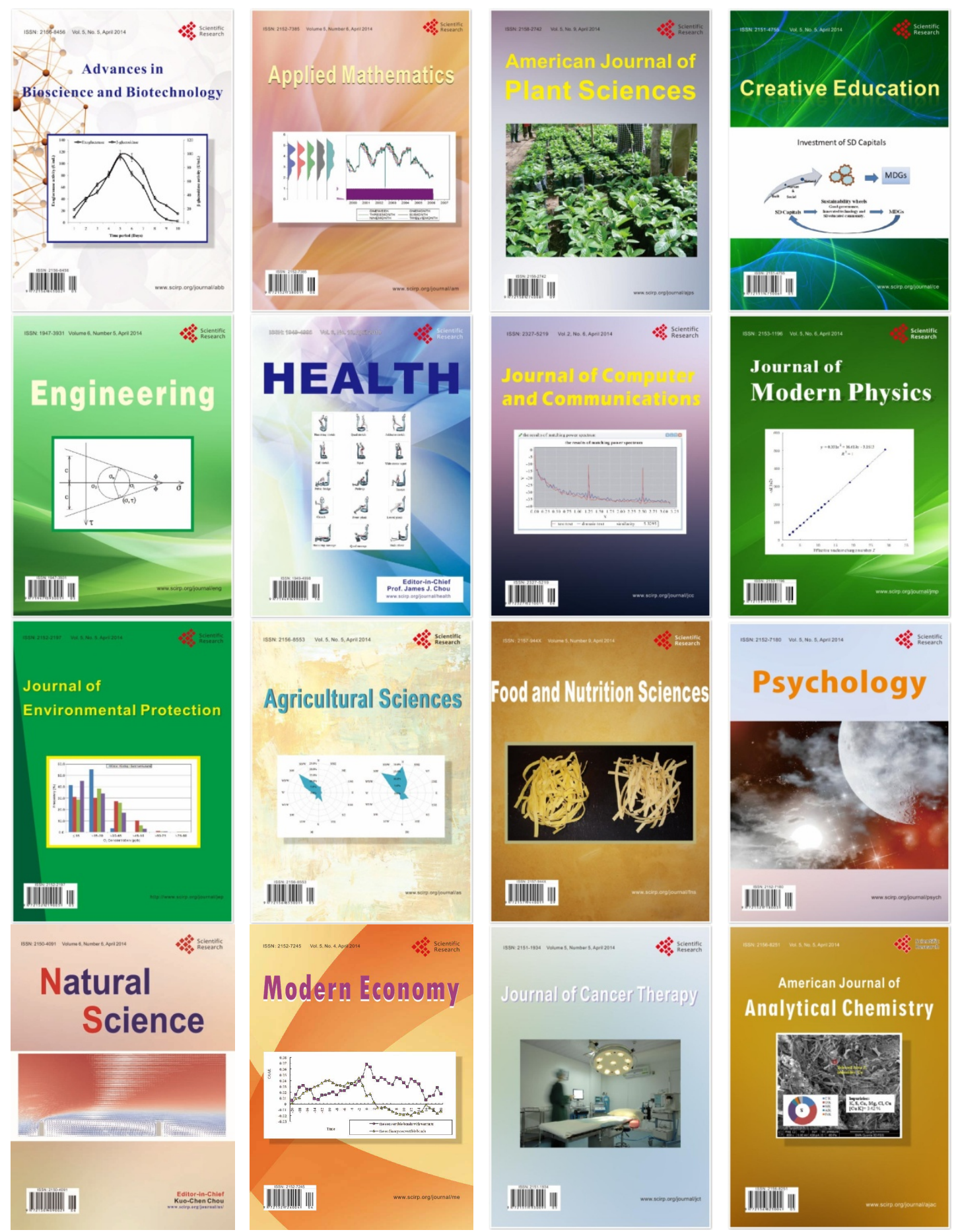